\title{
Children's sensitivity to pictorial depth information
}

\author{
RICHARD K. OLSON \\ University of Colorado, Boulder, Colorado 80302
}

\begin{abstract}
Children, ranging in age from 3 years, 4 months to 5 years, 4 months, were tested for sensitivity to interposition, height in field, linear perspective, and retinal size under either restricted (monocular, head motionless) or unrestricted (binocular, head free) picture surface viewing conditions. All of the subjects' relative depth responses (near vs. far) to two toy houses were remarkably accurate with interposition and or height in field pictcrial depth information. Retinal size had relatively little control over their responses, and the addition of linear perspective resulted in no significant improvement. Performance was nearly equivalent under the two viewing conditions, indicating young children's ability to take a "pictorial attitude."
\end{abstract}

Pictures are a unique source of perceptual information because their two-dimensional surface often represents depth in a three-dimensional space. This perceptual transformation, achieved with ease by pictorially experienced adults, may provide special difficulties for pictorially inexperienced adults and children. Cross-cultural studies show marked deficits of pictorial depth perception in pictorially inexperienced adult populations (Deregowski, 1972; Hudson, 1960; Miller, 1973). Static and motion pictures abound in the young Western child's environment, but what do they actually see of the depth dimension? Is a 3-year-old child's cognitive and experiential base sufficient to properly interpret pictorial depth information?

Wohlwill (1965) found that 6-year-old children could make depth judgments from photographic slides nearly as well as adults. Apparently pictorial depth perception skills develop before age 6 , but there is only fragmentary evidence regarding younger ages. Wilcox and Teghtsoonian's (1971) 3-year-old subjects were insensitive to pictorially induced size illusions that were relatively powerful for 9-year-old children and adults. Their method included presentation of two equal-area figures on a picture background. Subjects were asked to point to the figure that looked larger or smaller. Adults and 9-year-olds typically saw the figure that would be farther away, given the pictorial background, as larger, while 3-year-olds performed at chance levels. Liebowitz, and Judisch (1967) have also noted 3.5-year-old children's insensitivity to the Ponzo illusion. Studies of pictorial size and Ponzo illusions generally assume that the effects are due to a size-depth perceptual constancy mechanism. Thus the phenomenal size of equal-area retinal images in the picture plane would be a

\footnotetext{
This research was supported by the Council on Research and Creative Work at the University of Colorado. The author expresses his gratitude to Sandra Anderson and Susan Stengel, whose remarkable skills in working with children made this experiment possible.
}

function of their perceived distance in a pictured three-dimensional space.

Conclusions from size-illusion studies regarding young children's insensitivity to pictorial depth information are limited by several factors. The judgment required was of size, not depth, and the children may have disassociated the response objects from the pictorial background. Also, conflicting evidence has been presented by Benson and Yonas's (1973, Experiment III) finding of a size illusion ("fatness") effect in 3-year-olds with a well-integrated line drawing providing linear perspective information for depth. Another study by Yonas and Hagen (1973) presented back-projected slides of two objects. Texture perspective and height in field provided information for depth, and these variables significantly influenced the 3-year-olds' size judgments. Although the Benson and Yonas (1973) and Yonas and Hagen (1973) studies clearly point to the influence of perspective (texture and linear) information on 3-year-olds' size responses, perceptual size in these studies is not necessarily associated with depth. True depth responses could be bypassed or supplemented by a direct relative size comparison of the objects with their perspective background. For example, size judgments could be based on the number of texture elements occluded by each object.

The present study was designed to directly test young children's relative depth responses to several types and combinations of pictorial depth information. Depth judgments were obtained in two picture surface viewing conditions, monocular-head motionless and binocular-head free, to test the possibility that primary binocular disparity and motion parallax cues to picture surface flatness override or modify responses to secondary pictorial depth information. Testing of 3-year-olds was facilitated by a simple binary relative depth (nearest or farthest) discrimination task and qualifying trials with the same judgment in a three-dimensional array to ensure the children's conceptual mastery of the relative depth judgment. 


\section{METHOD}

\section{Subjects}

Sixteen children drawn from the married student housing project at the University of Colorado were divided equally by sex and number into two age groups: $40-48$ months, mean 44 months, and 56-64 months, mean 62 months. Two children in the younger and one in the older age group, all males, were rejected and replaced from the subject pool because they failed to discriminate red and green in the conceptual qualifying task.

\begin{abstract}
Apparatus
Conceptual qualifying and photographed test stimuli were placed on a white table which measured $565 \mathrm{~mm}$ on the sides $x 800 \mathrm{~mm}$ in the front and back and $603 \mathrm{~mm}$ in height. During three-dimensional qualifying sessions, a black curtain was draped around and above the sides and back of the table to block off extraneous stimulation in the testing room. Blue poster board, $559 \mathrm{~mm}$ in height, was placed vertically at the back of the table as a background for photographed test stimuli. For thest test trials, slides were projected by a Kodak Carousel projector onto a $1.5 \mathrm{x}$ $1.5 \mathrm{~m}$ rear-projection screen ( $\mathrm{Da}$ Lite), placed vertically at the front of the table. The size and angle of projection produced retinal images at the subject's viewpoint that were nearly equivalent to those produced by the three-dimensional photographed scene. The subject viewed both qualifying stimuli and test slides from a point $375 \mathrm{~mm}$ above and $1.4 \mathrm{~m}$ back from the table's front edge. The table surface viewing angle at a point midway between the two depth response objects was $15 \mathrm{deg}$. The direct distance from the subject's eye to this point was $1.448 \mathrm{~m}$. In the monocular/headmotionless condition, the subject sat behind an opaque screen and viewed the test slides through a $3.2-\mathrm{mm}$ viewing aperture which was opened and closed by a Gerbrands electronic shutter. A tube in the viewing aperture masked the edges of the photographic slides. The screen and shutter were removed for the conceptual qualifying task and the unrestricted viewing condition. All responses were rewarded by an automatic marble dispenser into a dish through a model elephant's trunk beside the subject.
\end{abstract}

\section{Stimuli}

The qualifying and photographed test stimuli were three pairs of red or green houses measuring $152.4 \times 101.6 \mathrm{~mm}, 127 \times 84.7 \mathrm{~mm}$, and $101.6 \times 67.7 \mathrm{~mm}$, made from construction paper and mounted on the front of $25-\mathrm{mm}$-thick wooden blocks (see Figure 1). The edges of the blocks were beveled so the subject could see only the flat face of the houses. There were two houses in each training and photographed scene, one red and one green. All pairs were separated in depth by $254 \mathrm{~mm}$, with the closest house $152 \mathrm{~mm}$ and the farthest house $406 \mathrm{~mm}$ from the stimulus table's front edge.

The particular lateral placement of stimulus pairs varied as a function of the interposition pictorial cue category. Interposition information was presented by overlapping the houses $25 \mathrm{~mm}$ over the observer's and camera's line of sight (Figures 1B, 1D, and 1F). In the no-interposition conditions (Figures $1 \mathrm{~A}, 1 \mathrm{C}$, and $1 \mathrm{E}$ ), houses were placed $50 \mathrm{~mm}$ apart along the line of sight.

Height in field information was provided by a $15-\mathrm{deg}$ viewing angle to the table surface (Figures 1C, 1D, 1E, and 1F). In the no-height-in-field conditions, stimuli were photographed so that the camera's line of sight and height above the floor coincided with the table surface (Figures $1 \mathrm{~A}$ and $1 \mathrm{~B}$ ). Note also that the front edge of the table is higher in the picture plane and was projected at the subject's eye level.

Linear perspective information was provided by a grid of 25.4- $\mathrm{mm}$ squares drawn on poster board with $2-\mathrm{mm}$-wide black ink lines (Figures $1 \mathrm{E}$ and $1 \mathrm{~F}$ ). In the no-surface perspective condition, stimuli were placed on a white poster board surface that produced no noticeable texture in the photographs.

The three cue categories described above were photographed singly and in combination to produce the six levels of pictorial information in Figure 1, A-F. In addition, each level of pictorial information was represented by three size categories. The house pairs in Figure 1, A-F, are the same physical size $(127 \times 84.7 \mathrm{~mm})$, and therefore the more distant house is smaller in the picture plane and on the retina. Considering the possibility that retinal size could be used as a depth cue, two additional size groups were included in the stimulus series. In one group, the near house was $127 \mathrm{x}$ $84.7 \mathrm{~mm}$ and the far house was $152.4 \times 101.6 \mathrm{~mm}$. Sizes of the houses in the picture plane were therefore equal (Figure 1G). In the second size group, the near house was $101.6 \times 67.7 \mathrm{~mm}$ and the far house was $152.4 \times 101.6 \mathrm{~mm}$, producing a larger image in the picture plane for the more distant house (Figure $1 \mathrm{H}$ ).

Six levels of pictorial information based on interposition, height in field, and linear perspective yielded an 18-item pictorial stimulus series when combined with the three size categories. In addition, left-right placement and color (red or green) of the farthest stimulus were counterbalanced, producing a complete stimulus series of 72 slides. Photographed stimuli were illuminated from several directions to exclude visible shadows and provide equal brightness of the near and far stimuli from the observer's point of view. Transparencies were produced from Kodachrome II professional film.

\section{Procedure}

The subject was brought into the experimental room and shown the prize (an "Itty Bittys" toy) he would receive when he finished the "game." He was then asked to sit in the chair in front of the stimulus table, and the chair height was adjusted for proper viewing level. In the initial conceptual qualifying trials, the subject was asked to verbally specify the color house that was closest or farthest in the three-dimensional array. Specification of correct response closest or farthest was counterbalanced over subjects within groups. House pairs in the qualifying trials were placed several inches apart laterally, thereby excluding interposition, and at a slightly greater depth separation than photographed stimuli. There were several other objects such as trees and toy animals present on the stimulus table surface. Size, color, and right-left placement of houses were randomly selected for each qualifying trial. All subjects met the training criterion of six consecutive correct responses within 12 trials, and most met criterion in the first 6 trials. Once they understood the task requirements, they had no trouble judging relative depth in the three-dimensional scene.

Following the qualifying trials, room lights were dimmed and subjects were immediately transferred to slide stimuli under one of two conditions, balanced for sex and age. Unrestricted subjects watched the experimenter put up the back-projection screen at the front of the stimulus table and were told to continue making the same depth judgment about the two houses in the picture that they made in the training session. Restricted viewing subjects had the opaque screen placed in front of them at the end of the training session and could not see the experimenter raise the back-projection screen. They were told to look through the viewing aperture and make the same judgment about the houses they saw as in the qualifying trials. No reference was made to the pictorial nature of the stimulus. The viewing aperture was closed when the slides were changed.

All responses, correct and incorrect, were rewarded with a marble from the automatic dispenser. Subjects were given general encouragement throughout the session. The entire 72-trial stimulus series was presented in one session with a different random order of trial presentations for each subject. The children were given a 5-min break after 36 trials. Even the youngest subjects remained attentive and task-oriented throughout the series. Most trials were presented approximately every $20 \mathrm{sec}$, and most sessions lasted between 20 and $30 \mathrm{~min}$.

\section{RESULTS}

Each response was assigned a 1 for correct and 0 for incorrect. The four counterbalanced responses in each 


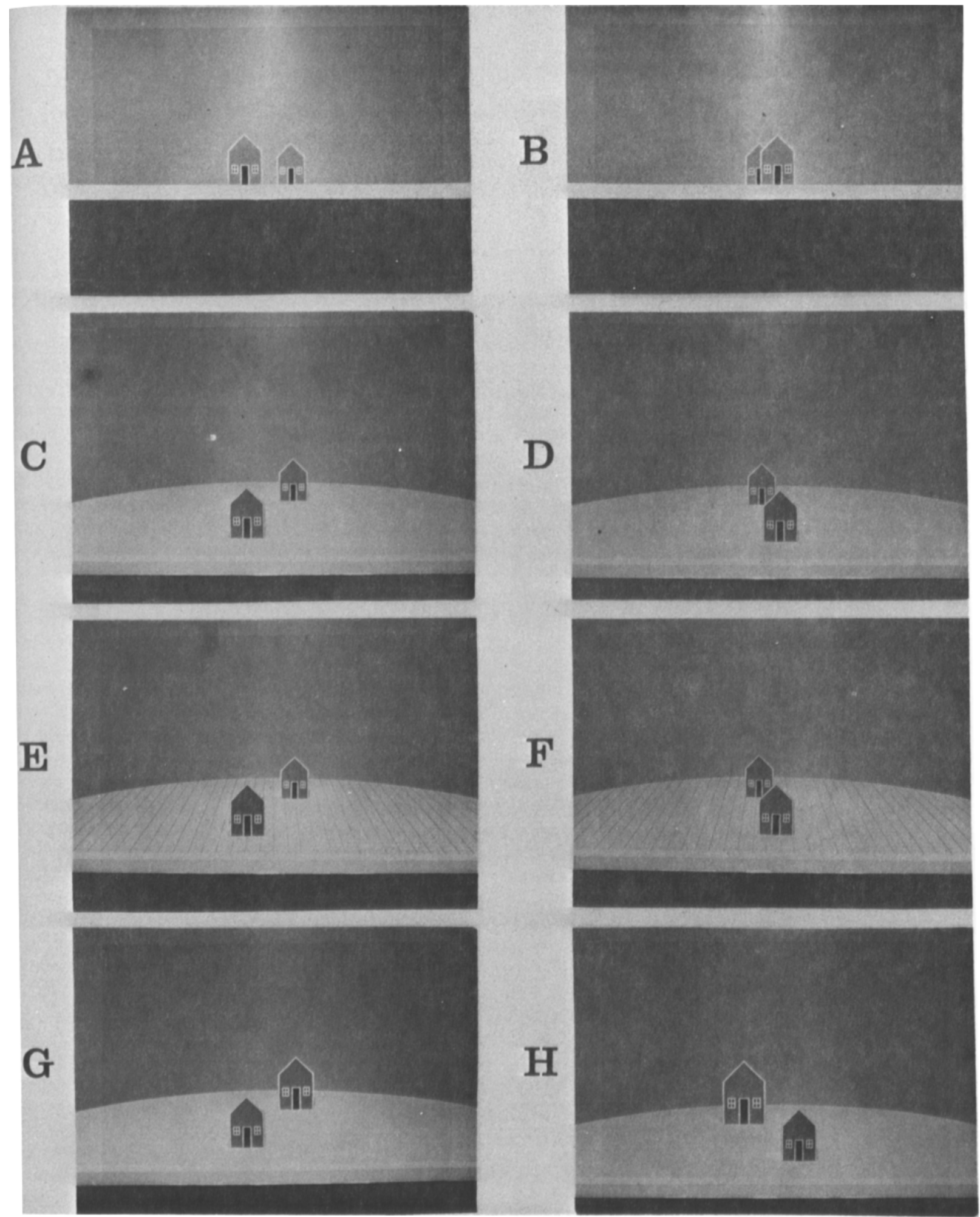

Figure 1. The picture stimuli. 
Table 1

Childrens' Mean Correct Responses to Retinal Size and Pictorial Cue Categories

\begin{tabular}{llcccc}
\hline Category & $\begin{array}{c}1 \\
\text { Descrip- } \\
\text { tion* }\end{array}$ & $\begin{array}{c}2 \\
\text { Iden- } \\
\text { tical } \\
\text { Physical }\end{array}$ & $\begin{array}{c}3 \\
\text { Iden- } \\
\text { tical } \\
\text { Retinal }\end{array}$ & $\begin{array}{c}\text { Far } \\
\text { Retinally } \\
\text { Larger }\end{array}$ & $\begin{array}{c}\text { Pictorial } \\
\text { Cue } \\
\text { Means }\end{array}$ \\
\hline 1 & No I, No H & 2.81 & 1.81 & 1.75 & 2.13 \\
2 & I, No H & 3.75 & 3.75 & 3.68 & 3.73 \\
3 & No I, H & 3.94 & 3.75 & 3.81 & 3.83 \\
4 & I, H & 4.00 & 3.94 & 3.81 & 3.92 \\
5 & No I, H, L & 3.81 & 3.81 & 3.75 & 3.79 \\
$6 \quad$ I, H, L & 3.88 & 3.94 & 3.94 & 3.92 \\
Size Means for & 3.70 & 3.50 & 3.46 & \\
Categories 1-6 & & & & \\
(Size Means for & 3.88 & 3.84 & 3.80 & \\
Categories 2-6) & & & &
\end{tabular}

${ }^{*} I=$ interposition, $H=$ height in field, $L=$ linear perspective.

Table 2

Analysis of Variance of Childrens' Pictorial Depth Responses

\begin{tabular}{|c|c|c|c|c|}
\hline Source & df & $\begin{array}{c}\text { Mean } \\
\text { Squares }\end{array}$ & F Value & $\stackrel{p}{p}$ \\
\hline Age (A) & $1 / 12$ & .0868 & .169 & n.s.* \\
\hline Viewing Condition (V) & $1 / 12$ & .0313 & .061 & n.s. \\
\hline Retinal Size (R) & $2 / 24$ & 1.5729 & 21.906 & $\mathrm{p}<.01$ \\
\hline Pictorial Cue (P) & $5 / 60$ & 23.7146 & 67.989 & $\mathrm{p}<.01$ \\
\hline AV & $1 / 12$ & .0035 & .006 & n.s. \\
\hline AR & $2 / 24$ & .0243 & .338 & n.s. \\
\hline VR & $2 / 24$ & 1.1354 & 15.813 & $\mathrm{p}<.01$ \\
\hline AP & $5 / 60$ & .4701 & 1.374 & n.s. \\
\hline VP & $5 / 60$ & .1812 & .519 & n.s. \\
\hline RP & $10 / 120$ & .8937 & 3.465 & $\mathrm{p}<.01$ \\
\hline AVR & $2 / 24$ & .4618 & 6.431 & $p<.01$ \\
\hline AVP & $5 / 60$ & 1.2368 & 3.545 & $p<.01$ \\
\hline ARP & $10 / 120$ & .1201 & .465 & n.s. \\
\hline VRP & $10 / 120$ & .8479 & 3.287 & $\mathrm{p}<.01$ \\
\hline AVRP & $10 / 120$ & .2579 & 1.677 & n.s. \\
\hline
\end{tabular}

${ }^{*}$ Not significant at $\alpha=.05$.

Table 3

Tukey Gap Test on Cue Categories

\begin{tabular}{lcc} 
& $\mathrm{Gp}(\mathrm{V} 1=6, \mathrm{~V} 2=120)$ & $\mathrm{p}$ Value \\
\hline Cue 1 vs. 2 & 18.870 & $\mathrm{p}<.01$ \\
Cue 1 vs. 3 & 20.094 & $\mathrm{p}<.01$ \\
Cue 1 vs. 4 & 21.078 & $\mathrm{p}<.01$ \\
Cue 1 vs. 5 & 19.607 & $\mathrm{p}<.01$ \\
Cue 1 vs. 6 & 21.078 & $\mathrm{p}<.01$ \\
Cue 2 vs. 4 & 2.206 & $\mathrm{p}>.05$ \\
\hline
\end{tabular}

of the 18 retinal size by pictorial cue categories in Table 1 were totaled for each subject. These values were entered in a 2 by 2 by 3 by 6 factorial analysis with two age groups, two viewing conditions, three retinal size categories, and six pictorial size categories. Results of the analysis of variance are presented in Table 2 .

Main effects of age and viewing condition were not signiticant. The mean number of correct responses over size and cue categories was 3.53 for the younger and 3.57 for the older subjects. Mean number of correct responses for restricted and unrestricted viewing were 3.54 and 3.56 , respectively. Values in Table 1 are averaged over age and viewing condition groups.

Retinal size and cue category were both highly significant main effects. Retinal size effect means are given in the bottom summary row of Table 1 . Note that most of the variability is found in Pictorial Cue Category 1, where retinal size is the only difference between the stimuli. The means in parentheses at the bottom of Table 1 are averages over the other five categories. They show a considerably smaller and statistically insignificant difference. The interaction described above for retinal size and cue category (RP) was significant.

The two-way Retinal Size by Viewing Condition interaction (VR) and three-way Retinal Size by Viewing Condition by Cue Interaction (VRP) were significant, because in Pictorial Cue Category 1 , retinal size influenced responses more under unrestricted viewing $(\mathrm{R} 1=3.375, \mathrm{R} 2=1.5, \mathrm{R} 3=$ $1.375)$ than under restricted viewing $(\mathrm{R} 1=2.25, \mathrm{R} 2$ $=2.125, \mathrm{R} 3=2.125$ ). Two other three-way interactions involved age and retinal size. An Age by Viewing Condition by Retinal Size interaction (AVR) was caused in Retinal Size Category 2, where older subjects did better under unrestricted viewing ( 3.46 vs. 3.54) while younger subjects did better under restricted viewing (3.63 vs. 3.38 ). The Age by Retinal Size by Pictorial Cue interaction (AVP) resulted from older subjects $(1=2.87,2=1.75,3=1.63)$ being more controlled than younger subjects $(1=2.75,2=$ $1.87,3=1.87$ ) by retinal size in their responses in Cue Category 1.

The cue category main effect variance was almost entirely due to Category 1. A Tukey gap test was applied to category differences, and the results are summarized in Table 3 . Category 1 is significantly different from all others, while there are no significant differences between Categories 2-6. Two questions can be asked about differences within Category 1 as a function of retinal size. First, does retinal size influence the subjects' responses in the absence of other pictorial information? The answer is clearly yes. Confidence intervals for Retinal Size Means 1, 2, and 3 in Cue Category 1 were $\mathrm{p}(2.29 \leqslant 2.81 \leqslant 3.34)=$ $.95, \mathrm{p}(1.37 \leqslant 1.81 \leqslant 2.26)=.95$, and $\mathrm{p}(1.18 \leqslant 1.75$ $\leqslant 2.32)=.95$, respectively. Retinal Sizes 1 and 3 are clearly different from each other and show a tendency for subjects to choose the smaller stimulus as farther in the absence of other information. However, size was not nearly as powerful as other kinds of pictorial information in this study. The second important result in Cue Category 1 was from Retinal Size Condition 2, which contained no size, height in field, linear perspective, or interposition information about 
the real object depth difference. The confidence interval, $p(1.37 \leqslant 1.81 \leqslant 2.26)=.95$, encompasses a mean of two correct responses that would be expected by chance. This indicates that there was no uncontrolled information for depth such as object brightness or other extraneous factors.

\section{DISCUSSION}

Subjects in both age groups gave remarkably accurate relative depth responses. Children in our sample apparently had a sufficient cognitive and experiential base to utilize pictorial depth cues. The lack of a significant main effect for age is somewhat surprising, and a celing effect seems to be the most likely explanation. The subjects' mean number of correct responses out of four trials, excluding Cue Category 1, was 3.84. In view of Gibson's (1969) finding of an increase with age in perceptual acuity over a wide range of tasks, age differences in pictorial response accuracy might be obtained with smaller depth separations. Small, but significant, age interactions will be discussed separately with viewing conditions, retinal size, and cue category main effects.

The absence of a viewing condition main effect suggests that children's pictorial depth judgments were not generally influenced by primary depth cues to picture surface flatness. Apparently they are already capable of ignoring primary information and take what Gibson (1969) refers to as a "pictorial viewing attitude." Benson and Yonas (1973) obtained a similar result in their study of children's responses to shading information for depth under restricted and unrestricted viewing conditions.

Retinal size yielded a significant main effect and an interaction with cue category. Most of the variance was present in Cue Category 1, where there was no other pictorial information for depth. Even in Cue Category 1 , retinal size was far less powerful than other pictorial cues in determining depth responses. Its relative weakness may have been due to the experimental context. First, houses of different sizes were used in the conceptual qualifying task. Second, the farthest house defined by Cue Categories 2-6 was either the same retinal size or larger in two-thirds of the trials. Subjects were never told to ignore retinal size, but they probably realized its irrelevance to real depth differences in this experiment. Retinal size might have a stronger influence if the experimental context favored an assumption of equal physical size.

Interaction of retinal size with viewing condition, and viewing condition by cue, were primarily due to a much stronger response to retinal size in Cue Category 1 under unrestricted viewing. With restricted viewing, retinal size had no significant effect on depth responses. We are at a loss to explain this result. The three-way interaction between age, viewing condition, and retinal size is also difficult to interpret. In Retinal Size Category 2, older subjects did better under unrestricted viewing while younger subjects did better under restricted viewing. No likely explanation seems to present itself. The last significant interaction between age, retinal size, and pictorial cue showed that older subjects' responses were slightly more controlled than younger subjects' responses by retinal size in Cue Category 1 . Perhaps older subjects adopt a more consistent strategy, given the ambiguity in Cue Category 1, and choose the smaller retinal size as more distant. This further suggests that the use of retinal size as a depth cue develops relatively later in age than the other pictorial cues.

The lack of significant differences between Cue Categories 2-6 suggests a ceiling effect. Any one of the cues was sufficiently powerful to give accurate depth responses, and combining several sources of information produced no significant advantage. Comparison of the strengths of cues such as height in field and interposition is theoretically impossible because they vary on distinct dimensions. How much height in field difference is equivalent to $50 \mathrm{~mm}$ of interposition? This type of test was not the experimental goal. Differences on each cue dimension were made sufficiently distinct to override possible acuity limitations and provide a direct test of children's sensitivity to the particular cue categories. The children responded consistently to both height in field and interposition information. Retinal size exerted moderate control over depth responses only when there were no other depth cues present. Inclusion of linear perspective produced no significant advantage over the other categories, although, again, there was little room for improvement.

It would be interesting to know the lower age limits for adequate performance in this task. Two-and-onehalf-year-olds are presently being run with this set of stimuli and a pointing response. Preliminary evidence places their performance level close to the older age groups. It is tempting to suggest a basic, innate capacity to respond to pictorial depth, but studies on infants' size constancy judgments (Bower, 1966) and cross-cultural research (Miller, 1973) point to the importance of experience. All of the subjects in our study had television in the home and a variety of picture books. Children without such experience should be compared with the present sample.

\section{REFERENCES}

Benson, C., \& Yonas, A. Development of sensitivity to static pictorial depth information. Perception \& Psychophysics, $1973,13,361-366$.

Bower, T. G. R. The visual world of the infant. Scientific American, 1966, 215, 80-92.

Deregowski, J. B. Pictorial perception and culture. Scientific American, 1972, 227, 32. 
Gibson, E. J. Principles of perceptual learming and development. New York: Appleton-Century-Crofts, 1969.

Hudson, W. Pictorial depth perception in sub-cultural groups in Africa. Journal of Social Psychology, 1960, 52, 183-208.

Liebowitz, H. W., \& Judisch, J. M. The relation between age and the Ponzo illusion. American Journal of Psychology, 1967, 80, 105-109.

MilleR, R. J. Cross-cultural research in the perception of pictorial materials. Psychological Bulletin, 1973, 80, 135-150.

WILCOX, B. L., \& Teghtsoonian, M. The control of relative size by pictorial depth cues in children and adults. Journal of Experimental Child Psychology, 1971, 11, 413-429.
Wohlwill, J. F. Texture of the stimulus field and age as variables in the perception of relative distance in photographic slides. Journal of Experimental Child Psychology, 1965, 2, 163-177.

Yonas, A., \& Hagen, M. Effects of static and kinetic depth information on the perception of size in children and adults. Journal of Experimental and Child Psychology, 1973, 15, 254-265.

(Received for publication March 13, 1974; revision received August 26, 1974.) 